\title{
obituary
}

\section{Dr Alexander Hamilton Leighton, MD, FRCPC, FRCPsych (Hon.)}

Dr Leighton passed away quietly on 11 August 2007, at his home in Nova Scotia, shortly after his 99th birthday.

Born in Philadelphia, Pennsylvania, he came to Nova Scotia with his parents for the first time in 1916 at the age of 8 . This visit began an enduring relationship with Nova Scotia, where he made a lasting contribution to medical research and public health. He showed early interest in exploring the landscape, in the beauty of the province and in its natural history.

Alex studied biology at Princeton University. He was particularly interested in animal behaviour and received his $A B$ in 1932. He then went up to Cambridge University for premedical studies, earning his MA in 1934, after which he proceeded to Johns Hopkins University where he received his MD in 1936. This was followed by internship and residency in psychiatry at Johns Hopkins, where he was strongly influenced by Adolf Meyer. While there, he was granted a Social Science Research Fellowship sponsored by Columbia University, which allowed him to carry out field work among the Navaho and the Yup'ik of St Lawrence Island. In 1941, he joined the US Navy Medical Corps, where he remained until 1946, leaving with the rank of Commander. During that time, he conducted studies among relocated Japanese-Americans in Arizona and became a member of the Office of War Information as well as leader of the PostWar Strategic Bombing Survey in Japan, which analysed the impact of the atomic bomb on Japanese civilians. In 1946, he was appointed Professor in the Department of Sociology and Anthropology at Cornell University, an appointment he held until 1966.

In 1948, he initiated the first of the post-war studies of the distribution and amount of mental illness in a general population. Named the 'Stirling County Study', this investigation concerns an area in Atlantic Canada and is now directed by his wife, Dr Jane Murphy. One of the first

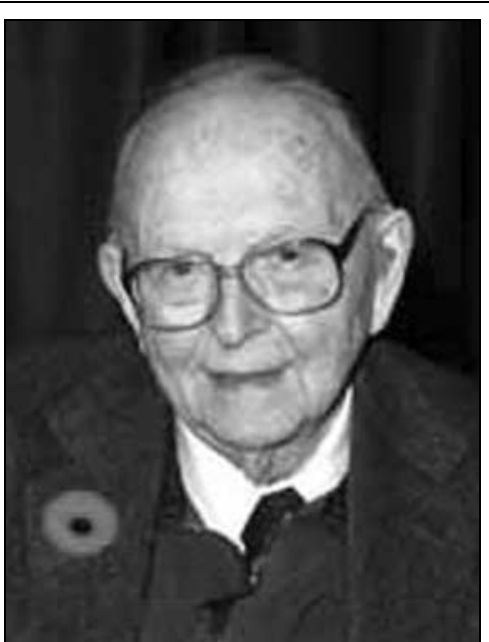

senior advisor to various foundations, government departments, and international organisations, including the World Health Organization. He was an Honorary Fellow of the Royal College of Psychiatrists in the UK and a member of the Society of Scholars of Johns Hopkins University; he held honorary doctorates from Acadia University and Université Laval. He received a Rema Lapouse Award from the American Public Health Association, a McAlpin Award from the US National Association for Mental Health, and a Joseph Zubin Award from the American Psychopathological Association. He was one of the founders of the American Society for Applied Anthropology and was also instrumental in the founding of the Canadian Academy of Psychiatric Epidemiology.

In 1998 in Halifax, to honour Professor findings was that about one in five adults has some sort of mental illness at any given time, with the most common being illnesses that involve depression, anxiety and alcohol misuse. Concerned to see whether other areas would show similar findings, Dr Leighton and Dr Murphy carried out several similar studies in other settings such as New York City, Alaska, Nigeria and Vietnam. Follow-ups to the Stirling County studies are still being conducted today, actively led by $\mathrm{Dr}$ Murphy. These studies have a theoretical framework that integrates somatic, psychological and cultural components.

A feature of Alex's career was his ability to strike a balance between fundamental research and applied programmes. For example, he directed the Cornell Program in Social Psychiatry, amalgamating the separate Midtown and Stirling County projects. This was followed by his appointment as Professor of Social Psychiatry and Head of the Department of Behavioral Sciences at the Harvard School of Public Health, posts he held until 1975. Following this, he was for 10 years a Canadian National Health Scientist in the Department of Psychiatry at Dalhousie University.

Alex received numerous national and international awards covering a wide range of scientific fields and acted as
Leighton as a pioneer and leader of

Canadian psychiatric epidemiology at his 90th birthday, the Canadian Psychiatric Association and the Canadian Academy of Psychiatric Epidemiology created the Alex Leighton Award. This award recognises that his work associated innovative scientific endeavours with humanistic values and social concerns.

Professor Leighton was a great and inspired generations of psychiatric epidemiologists and scientists. Those of us working in the field of psychiatric epidemiology, transcultural psychiatry, the sociology of mental health, and anthropology as related to mental health and mental illness owe a debt of gratitude to Alex for his leadership and example, his outstanding scholarship, his ethical approach, his warm friendship and his encouragement.

Alex is survived by his son, daughter and five grandchildren, and by his wife, devoted companion and outstanding scientific colleague, Dr Jane Murphy.

Roger Bland

Reproduced with kind permission from (an Psychiatry (2007) 52, 615-616.

doi: 10.1192/pb.bp.108.023697 communicator and teacher who trained 